\title{
Exploring the development of students' conceptual profiles of chemical change
}

\author{
Núria Solsona, Fosep Pla Secondary School, Barcelona, Spain; Mercè \\ Izquierdo, Autònoma University in Barcelona, Department of Didactics of \\ Science and Mathematics, Barcelona, Spain; Onno de Fong, Utrecht \\ University, Department of Chemical Education, The Netherlands
}

\begin{abstract}
A naturalistic small-scale study was carried out, involving a class from a senior high school in Spain over two years. The students were requested on two occasions to write an essay about chemical change. The essays were subjected to text analysis techniques. Four conceptual profiles were identified: the interactive, the meccano, the kitchen, and the incoherent. The development of these profiles is reported and the implications of our research for the process of teaching the concept of chemical change are given.
\end{abstract}

\section{Introduction}

The concept of chemical change is a central concept in the chemistry curriculum for the secondary school. Students should learn to interpret this concept in two domains: the macroscopic domain and the microscopic domain. The macroscopic domain deals with substances and their properties, science processes and phenomena. The micro-domain deals mainly with corpuscular models, such as molecules, atoms, ions and electrons. From a 'macro' point of view, chemical reactions are considered as a process by which some substances disappear and new substances appear. From a 'micro' point of view, chemical reactions are considered as a process by which particles are re-ordered. Students also have to learn to relate the two domains by using representations such as icons and diagrams. In the case of chemical change, representations such as formulas and reaction equations play an important role.

In the last two decades, a great deal of research has been focused on students' difficulties in understanding the concept of chemical change (Llorens 1991, Hesse 1992, Stravridou et al. 1993, Martín 1994, Brinkman and de Jong 1996). Several more specific studies have been carried out focusing on students' understanding of the concept of substance (Solomonidou 1991, Roletto and Piacenza 1994), element and compound (Martinand 1986, De Vois and Verdonk 1987, Ramsden 1997), and the distinction between chemical change and physical change (Meheut 1989, Brosnan 1990).

Andersson (1990) proposed five categories in order to describe students' knowledge of chemical change. These five categories are: disappearance, displacement, modification, transmutation and chemical interaction. In the first four 
categories, students interpret the appearance of new substances and the disappearance of the original substances as a result of changes which are not related to these original substances. The original substances may interact with other substances but they are not part of the new substances. Watson et al. (1995) discuss the usefulness of Andersson's (1990) categories in order to analyse students' knowledge in relation to combustion, because they consider disappearance as a limiting case of transmutation. They classify students' knowledge according to the categories of chemical change, transition, transmutation and others. The category of transition includes those answers which are between the categories of chemical change and transmutation.

Sannmartí et al. (1995) analysed the explanations of 13-year old students regarding the properties of substances and their changes. A significant number of pupils use explanations which have been categorized as 'substantialisation of properties'. It is said that students substantialize a particular property when they treat the property as a material substance. For instance, when sugar is dissolved in water, students believe that sugar disappears, but only the taste remains. This kind of idea had been important in the historical development of chemical knowledge. The authors classified students' answers according to three categories: substantializers, non-substantializers and not-expressing-a-model.

To summarize, research in chemistry education has been mainly focused on the learning of chemical concepts, on how different concepts are being used by students, and on how students construct propositions and rules with concepts (Thagard 1990) in order to produce explanations for chemical phenomena. Researchers have established various categories in order to classify students' conceptions. Our research deals with the 'problematic' issue of how to learn to interpret phenomena of change (substances disappearing and new ones appearing), in terms of unchanged entities (atoms). In this article, we will report on the development of secondary school students' processes of reasoning, taking into account that these students have to learn how to relate macro-descriptions of chemical change to micro-descriptions.

\section{Scope of the study}

In our study, the process of learning is considered from a constructivist point of view. According to this perspective on knowledge acquisition (Driver 1989), learning is a dynamic social process which allows learners to actievely construct meaning from their actual experiences, in connection with their prior understanding and the social setting. Knowledge and learning are considered as fundamentally situated, that is to say, cognition is part of the activity, context and culture in which it is developed and used.

In order to analyse students' conceptual development, Mortimer (1993) used the notion of 'conceptual profile', which is composed of different levels of understanding. He illuminates this notion by referring to the concept of mass. The first level of understanding corresponds to everyday notions about mass which are strongly rooted in common-sense reasoning. The second level of the profile corresponds to an objective determination of mass using measure scales. The next level is related to the use of mass within a conceptual network and not merely as a primitive and immediate experience, as used by Newton. The final 
level corresponds to the concept of mass in the context of the relativity paradigm, as used by Einstein.

Mortimer (1993) suggests that, even in scientific domains, there are epistemological and ontological differences between successive theories. For instance, he has developed the conceptual profile of the atomistic explanation of matter, in which every level shows a particular degree of conceptualization of the concept of atom. The first level of the atomistic profile is a realist one and it is characterized by the absence of any discontinuous notion of matter. The second level is called substantialist atomism, in which the atoms are treated as a material substance: they are yellow if the substance is yellow. The third level corresponds to the traditional notion of the atom as the basic unit of matter, which is conserved during chemical transformations. The final zone of the profile reflects the quantum mechanical treatment of the atomic system. This example also illustrates that a conceptual profile can be considered as a 'vertical' profile.

We use the term conceptual profiles as a synonym for school theory. In the process of learning, students construct a body of knowledge about chemical phenomena, and interpretations of these phenomena. Students' conceptual profiles will evolve in this process. The consecutive levels of conceptual profiles reflect the ability of students to give coherence and meaning to the diversity of facts that they encounter, both in the chemistry classroom and outside. These conceptual profiles will become more useful and accurate, because the students will become more and more competent at interpreting chemical phenomena, identifying properties of reactants and products and talking both about the macroscopic and microscopic levels.

The present study focuses on students' conceptual development of the concept of chemical change. Students involved in the study came from the final two years of senior high school in Spain (Solsona 1997, Izquierdo and Solsona 1999). Their cognitive development will be described in terms of conceptual profiles. The research questions were: Which conceptual profiles about the concept of chemical change can be identified among secondary school students?; How can the development of such profiles during consecutive years of secondary school be characterized?

\section{Method}

\section{Research design}

The students were Spanish students of a standard senior high school in Barcelona. In this school, the curriculum includes three chemistry courses (grades 10-12), out of which two take only part of the year, from February to June. The topic of chemical change is first taught to students in grade 10 (students about 16-years old).

Practical work in secondary schools is not usual in Spain and the textbooks that are used do not contain experimental work tasks. However, the chemistry teacher who was involved in our research project used practical work in the classroom and set up student experiments and demonstration experiments (Solsona and Izquierdo, 1998).

Research data were obtained from students' assays about chemical change. The essays were written by the same students on two occasions: at the beginning 
of the second school year (grade 11) and one school year later. We chose the beginning of the second and third school years, after a school holiday period, because we wanted to investigate what knowledge of chemical change students had just before a new year of chemistry learning.

\section{Subjects}

There were 51 students involved, aged 17 at the beginning of the research and 18 when it was finished. They were 22 girls and 29 boys belonging to two classes in the same grade from the same high school. In both cases of essay writing, the same group of students was involved.

\section{Collecting research data}

The first time we collected research data was at the beginning of the second school year for students in grade 11. At that time, the topic of chemical change had been taught, in the first year of schooling, using a usual textbook. The period of time for chemistry education had been of two months, from May to June. Students were taught chemical change as a process of formation of new substances as well as a process of atomic re-ordering. They were also taught several other chemistry topics, viz pure substance, chemical element as a substance with a specific kind of atoms, and the concept of conservation within chemical change.

Practical work done during the first year includes separation of mixtures, reaction between sulphur and iron, electrolysis of water, synthesis of water, and the copper cycle. Experiments had been carried out during schooltime, and the teaching strategy followed the learning cycle (Cosgrove and Osbourne 1991), that includes learning activities for each one of the following phases: exploration of the concept, introduction of the concept, and application of the concept.

All students were asked to write an essay about chemical change. More specifically, they were asked to write down everything they could remember about chemical change, mentioning explicitly the concepts necessary to explain it, the best examples of chemical change and an explanation at a microscopic level (Solsona and Izquierdo 1993).

The essays were written individually in the classroom. The first time they did not need more than half an hour. Each student wrote a one-page essay in average. In this article, the collected essays will be indicated as 'essays I'. The second time to collect research data was one year later, at the beginning of students' third school year, grade 12. This year is also the final year for high school students. In between, students were taught several new chemistry topics, viz atomic structure, periodic system, chemical bonding and stochiometry, by using a well-known textbook. The period of time for chemistry education had been five months, from February to June. Students had been taught by the same teacher who followed the same teaching strategy as the year before, and organized practical work regarding new chemical topics. He also repeated a former experiment within the copper cycle, in order to reinforce the learning of the concept of conservation in a chemical change. The 51 students were asked to write an essay again individually. The second time they did not need more than half an hour and each student wrote an essay of about two pages. In this article, their essays will be indicated as 'essays II'. 


\section{Analysing data}

Initially, we tried to analyse all the essays using devices such as double entry tables or those systems of categorization used in other qualitative studies including essay analysis (Brosnan 1990, Andersson 1990). However, we realized that, in our case, these instruments could not identify the main ideas in each essay.

For this reason we decided to analyse all the essays using a set of categories which was based on the method of linguistic analysis described by Van Dijk (1978). This approach allows us to consider a written text as a unit of meaning and intention, which can be understood as a discourse between the writer (in our case, the student) and the reader (in our case, the teacher).

We decided to analyse the semantic microstructure of the texts as well. The term 'semantic microstructure' refers to the structure of propositions or ideas and their relationships (Van Dijk 1978). In order to study this structure in a more specific way, we have decided to develop maps of the text structures, in the way described by Thagard (1990). A Thagard map can be considered as a concept map but it gives more information. It includes not only the concepts and the relationships between concepts, but it also shows which kind of relationships can be indicated: property, class, rule, part, example.

Thagard maps of the semantic microstructure were used to develop content categories to compare 'essays I' with 'essays II'. After an iterative process of developing categories, the following five categories were established: kind of change produced during chemical change; conservation within chemical change; level of explanation of chemical change; examples of chemical change; and global coherence of the text. Each category is split up into subcategories.

Regarding the category of the kind of change during chemical change, we distinguish the following subcategories: change at the substance level, where a new substance with different properties is formed; physical change; change of properties, though it is uncertain whether a new substance is formed; change of structure, when the change is only at the microscopic level; and finally, no change statements given. Regarding the category of conservation within chemical change, we distinguish the following subcategories: conservation when students speak about mass conservation or element conservation; and, no conservation statements given. Regarding the category of the level of explanation of chemical change, we distinguish the following subcategories: macroscopic; microscopic and macro/micro relationship; and finally no relationship statements given. Regarding the category of examples of chemical change, we distinguish the following subcategories: 'empirical' examples; 'theoretical' examples; and no examples given. We consider examples as 'empirical' when they refer to the school laboratory or to everyday life (e.g. burning a piece of paper). We consider examples as 'theoretical' when they refer to representations, as a chemical reaction equation, a drawing using the 'ball' model and so on. Regarding the category of global coherence of the text, we distinguish the following subcategories. We say that the text coherence is strong when all the concepts mentioned in the text are interrelated. We claim that the text coherence is weak when some of the concepts are interrelated but some others are not. We state that the there is no global coherence in the text, when the text is a set of disconnected ideas.

At the end of the analysis, we have established an overall category 'concept of chemical change', including the following subcategories. We say that students have 
explained the concept of chemical change when they explain changes as changes of substances interrelating correctly the macroscopic and microscopic levels. We say that it is uncertain that students have explained the concept of chemical change when they explain changes only as changes of structure or as physical changes without establishing the correct interrelation between the macroscopic and microscopic levels, while they are not able to write a text about it with global coherence. We say that students have not explained the concept of chemical change when they do not explain changes at any level of explanation.

To enhance the reliability of the analysis results, the first author has repeated the analysis. She has obtained no significant differences. In order to enhance the validity too, the second author has also carried out the analysis. Again, no significant differences were obtained.

\section{Results}

The main results of the analysis of the essays are given in table 1 . The subcategories given in table 1 have been used to develop four conceptual profiles of chemical change (figure 1). In the process of developing these profiles, the category 'conservation in chemical change' was deleted because of the low scores on this category: about $80 \%$ of the essays are lacking statements regarding conservation of mass or element. We have named the four profiles: interactive, meccano, kitchen, and incoherent profile.

Essays which belong to the interactive profile have the following characteristics. Chemical change is interpreted in terms of a change of substances, that

Table 1. Results of the analysis of the essays.

\begin{tabular}{|c|c|c|c|c|c|}
\hline \multirow[b]{2}{*}{ Category } & \multirow[b]{2}{*}{ Subcategory } & \multicolumn{2}{|c|}{ Essay } & \multicolumn{2}{|c|}{$\begin{array}{c}\% \text { of essays } \\
(\mathrm{n}=51)\end{array}$} \\
\hline & & $I$ & $I I$ & $I$ & $I I$ \\
\hline \multirow[t]{5}{*}{ Kind of change } & substances & 22 & 5 & 43 & 10 \\
\hline & physical change & 5 & 8 & 10 & 16 \\
\hline & properties & 10 & 5 & 20 & 10 \\
\hline & structure & 11 & 17 & 21 & 33 \\
\hline & no statements & 3 & 16 & 6 & 31 \\
\hline \multirow[t]{2}{*}{ Conservation } & mass or element & 10 & 8 & 20 & 16 \\
\hline & no statements & 41 & 43 & 80 & 84 \\
\hline \multirow[t]{4}{*}{ Level of explanation } & Macroscopic & 29 & 11 & 57 & 22 \\
\hline & Microscopic & 13 & 20 & 26 & 39 \\
\hline & Macro/micro & 6 & 4 & 11 & 8 \\
\hline & no statements & 3 & 16 & 6 & 31 \\
\hline \multirow[t]{3}{*}{ Examples } & empirical & 38 & 21 & 74 & 41 \\
\hline & theoretical & 5 & 14 & 10 & 28 \\
\hline & no statements & 8 & 16 & 16 & 31 \\
\hline Global coherence & strong & 50 & 5 & 98 & 49 \\
\hline \multirow[t]{2}{*}{ of the text } & weak & 1 & 5 & 2 & 10 \\
\hline & no statements & 0 & 20 & 0 & 39 \\
\hline Concept of & yes & 6 & 4 & 11 & 8 \\
\hline \multirow[t]{2}{*}{ chemical change } & uncertain & 42 & 34 & 83 & 66 \\
\hline & no & 3 & 17 & 6 & 33 \\
\hline
\end{tabular}




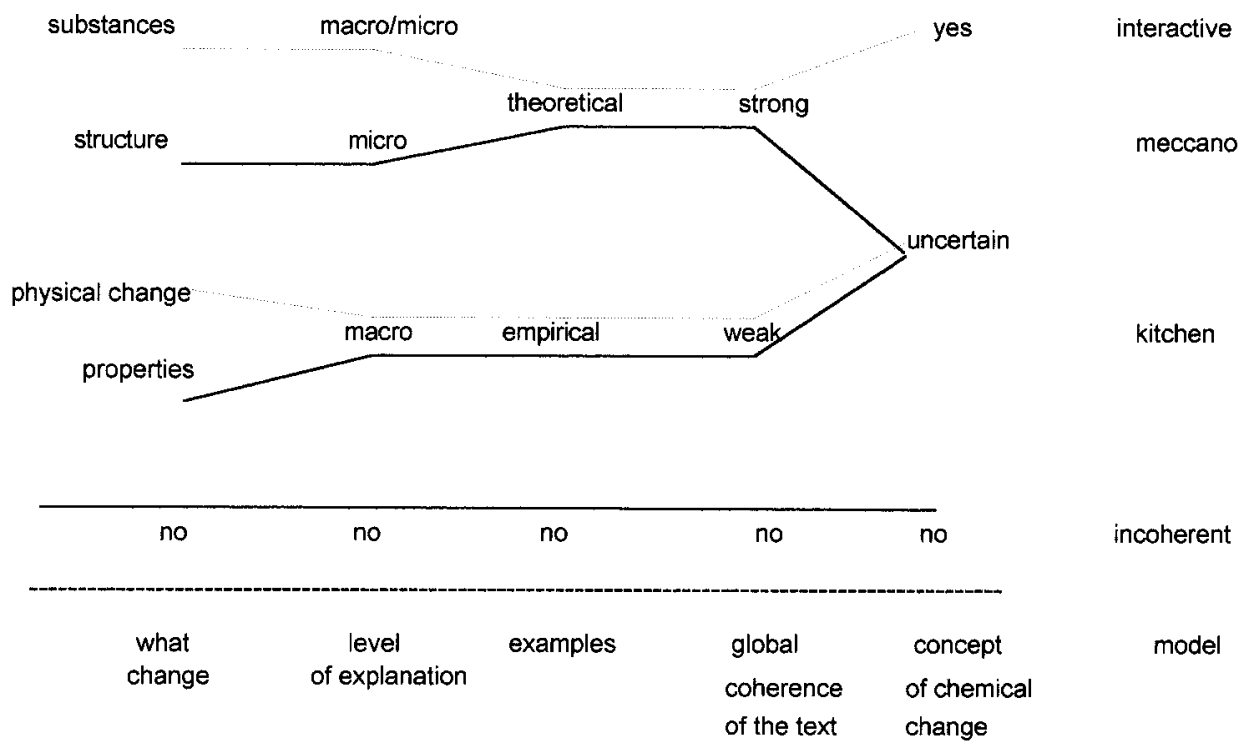

Figure 1. Four conceptual profiles of chemical change.

is, of formation of new substances which replace the initial ones. There is a coherent and balanced relationship between the macroscopic and microscopic levels of explanation. The examples given are theoretical ones, and the text is coherent on a global basis. The scientifically accepted model of chemical change has been acquired.

Essays which belong to the meccano profile have the following characteristics. Discourse is built up fundamentally around the microscopic explanation of change, without paying attention to phenomena. Change is dealt with at the level of internal structure. Examples are theoretical and the text has weak coherence on a global basis. It is unclear whether the scientifically accepted concept of chemical change has been acquired.

Essays which belong to the kitchen profile have the following characteristics. Discourse is mainly built around phenomena. Chemical change is described as a physical change or as a change of properties. The examples given are empirical ones, and the text has weak coherence on a global basis. The level of explanation is mainly macroscopic. It is unclear whether the scientifically accepted model of chemical change has been acquired.

Essays which belong to the incoherent profile have the following characteristics. Chemical change is not explained. The examples of change that are given are not reasoned. No clear terminology is used, neither macroscopic nor microscopic. The text does not have global coherence; in fact, discourse does not follow an ordered thematic progression. In most cases, only a list of lessons, things and definitions is given.

All the essays have been grouped in these four conceptual profiles, and the results are given in table 2 . 
Table 2. Essays I and II related to conceptual profiles.

\begin{tabular}{llclc}
\hline $\begin{array}{l}\text { Profiles of } \\
\text { chemical change }\end{array}$ & \multicolumn{1}{c}{$\begin{array}{c}\text { Number of } \\
\text { essays I }\end{array}$} & $\begin{array}{c}\text { Percentage } \\
\text { essays } I\end{array}$ & $\begin{array}{c}\text { Number of } \\
\text { essays } I I\end{array}$ & $\begin{array}{c}\text { Percentage } \\
\text { essays II }\end{array}$ \\
\hline Interactive & 4 (1 girl, 3 boys $)$ & $8 \%$ & 4 (1 girl, 3 boys $)$ & $8 \%$ \\
Meccano & 13 (4 girls, 9 boys $)$ & $25 \%$ & 17 (8 girls, 9 boys $)$ & $33 \%$ \\
Kitchen & 27 (13 girls, 14 boys $)$ & $53 \%$ & 13 (4 girls, 9 boys $)$ & $25 \%$ \\
Incoherent & 7 (5 girls, 2 boys) & $14 \%$ & 17 (10 girls, 7 boys $)$ & $33 \%$ \\
\hline
\end{tabular}

\section{Discussion and implications}

This study shows that we can identify four conceptual profiles of chemical change: the interactive profile, the meccano profile, the kitchen profile and the incoherent profile. An analysis of the first essays shows that most of the students (53\%) reason according to the kitchen profile; in the first year, the attention of these students is mainly focused on chemical phenomena. A relatively large amount $(25 \%)$ of students reason according to the meccano profile. They have conceptions of chemical change that do not pay attention to chemical facts studied in class and experimented in the laboratory; they give more importance to the microscopic level of explanations by referring to atoms, electrons, bonding, etc.

From the analysis of the second essays, most of the students are distributed in almost equal percentages between the meccano profile $(33 \%)$, the kitchen profile $(25 \%)$, and the incoherent profile $(33 \%)$. Only $8 \%$ of students reason according to the interactive profile. These results mean that a vast majority $(92 \%)$ of students are not able to understand the concept of chemical change in a balanced way, that is to say, by relating the macroscopic meaning to the microscopic meaning of this concept.

Another point of view for the analysis allows us to compare each profile in terms of the essays. Table 2 shows that the interactive profile has the same percentage in essays I and II. The interactive profile is closely related to the scientific explanation of chemical change. These results show that increasing the number of lessons about chemical change and other chemical concepts does not ensure that students understand this concept better and in a more scientific way.

Comparison between both essays also shows that the percentage of students with the kitchen profile decreases (from 33\% to 25\%), while the percentage of students with the meccano profile increases (from $25 \%$ to $33 \%$ ). Fewer students reason about chemical change only at the macroscopic level, while more students reason only at the microscopic level. This may be because of the lessons inbetween. Surprisingly, and contrary to our expectations, the results also indicate that there had been a worrying increase in the number of essays belonging to the incoherent profile. These remain to be interpreted.

Two conceptual profiles are of particular interest: the kitchen profile and the meccano profile. Students who are identified with the kitchen profile have strong mental links with chemical phenomena. For them, it is useful and meaningful to remember experiments and the behaviour of substances used in the laboratory in order to understand chemical change. However, for students grouped in the meccano profile, it is useful and meaningful to remember atoms, electrons and bonding in order to understand chemical change. 
At a methodological level, our research uses a new type of analysis of the essays. We have not only analysed the superficial contents of the essays, in other words, we have not only reported whether students refer or not to chemical concepts, such as particles, or properties of substances. We have also connected students' use of some chemical concepts with other concepts. Students have to learn how to relate macroscopic and microscopic concepts in order to give an explanation of chemical phenomena. For that reason, in the analysis of essays, we have included a semantic component referring to the semantic microstructure of the text (Thagard 1990). This allows us to pay attention to the coherence of explanations of chemical change given by the students. The four conceptual profiles enable us to express to what extent the students have built up the concept of chemical change in their essays, taking into account their indications of chemical phenomena and accompanying explanations.

Our research has two implications for teaching. The first one is that not all students' explanations are incorrect. In fact, most of the time, they are incomplete or partially correct. As we can see in the kitchen and meccano profiles, some students produce their explanations of chemical phenomena by referring only to the macroscopic level or chemistry or only to the microscopic level of chemistry. Teachers should manage classes in such a way that students become aware or their own ideas about chemical phenomena. As a consequence, they would be able to understand that some of their explanations can be completed with others. In this way, students could learn to understand the usefulness of relating the macroscopic meaning of chemical change to the microscopic meaning.

The second implication refers to the fact that many students do not remember the experiments done in the classroom. They do not incorporate content information from the experiments in their essays. We mention this aspect because the incorporation of phenomena studied in the laboratory or seen in everyday life is, in our opinion, necessary for the meaningful construction of the interactive profile of chemical change. It is difficult to find crucial experiments at the beginning of senior high school, but it is obviously not enough to refer to only one experiment conducted during the early phase of learning about chemical change.

The last implication of our research refers to examples of chemical phenomena which can be used in classrooms in Spain. These kind of examples are the first reference that students have in their process of construction of the conceptual profile of chemical change. The examples most frequently given by students were: reaction between sulphur and iron (in the first essay); and synthesis of water (in the second essay). These examples, which are described in Spanish textbooks and which we consider as typical of the Spanish chemistry curriculum, lead us to realize how important it is to select the appropriate textbook, as well as other educational materials (Fensham 1994, De Jong 1996, White 1996). It is necessary to investigate which kind of examples in textbooks or other educational materials will be useful to help students to construct an interactive profile of the concept of chemical change. This is a challenge for further research, in Spain as well as in other countries.

\section{References}

Andersson, B. (1990) Pupils' conceptions of matter and its transformations (age 12-16). Studies in Science Education, 18, 53-85. 
Brinkman, F. and De Jong, O. (1996) Science and mathematics teacher education: some themes of general interest. European Fournal of Teacher Education, 19, 103-107.

Brosnan, T. (1990) Categorising macro and micro explanations of material change. In P. Lijnse et al. (eds) Relating Macroscopic Phenomena to Microscopic Particles: A Central Problem in Secondary Science Education (Utrecht: CD-B Press).

Cosgrove, M. and Osbourne, R. (1991) Modelos didácticos para cambiar las ideas de los alumnus. In R. Osbourne and P. Freyberg (eds) El aprendizaje de las Ciencias (Madrid: Narcea), 166-184.

De Jong, O. (1996) La investigación activa como herramienta para mejorar la enseňanza de la química: nuevos enfoques. Enseñanza de las Ciencias, 14, 279-288.

De Vos, W. and Verdonk, A. (1987) A new road to reactions. Part 5. The elements and its atoms. Fournal of Chemical Education, 64, 1010-1013.

Fensham, P. (1994) Beginning to teach chemistry. In P. Fensham, P. Gunstone and R. White (eds) The Content of Science: A Constructivist Approach to its Teaching and Learning (London: The Falmer Press).

Hesse, J. J. (1992) Students' conceptions of chemical change. Fournal of Research in Science Teaching, 29, 277-299.

Izquierdo, M. and Solsona, N. (1999) The case of teaching and learning the concept of chemical change. In O. De Jong et al. (eds) Bridging the Gap between Theory and Practice: What Research says to the Science Teacher (Hong Kong: ICASE).

Llorens, J. A. (1991) Comenzando a aprender quimica (Madrid: Visor).

Martin, R. (1994) El conocimiento del cambio químico en la formación inicial del profesorado. Estudio de las concepciones disciplinarias y didácticas de los estudiantes de Magisterio. $\mathrm{PhD}$. thesis, Universidad de Sevilla.

Martinand, J. L. (1986) Connaitre et transformer la matière (Berne: Peter Lang).

Meneut, M. (1989) Das representations des élèves au concept de réaction chimique: premierères etapes. Bulletin de l'Union des Physiciens, 716, 15-27.

Mortimer, E. (1993) Studying conceptual evolution in the classroom as conceptual profile change. In B. Gowin (ed.) Third International Seminar of Misconceptions and Educational Strategies in Science and Mathematics (New York: Cornell University).

Ramsden, J. M. (1997) How does a context-based approach influence understanding of key chemical ideas at 16+? International Fournal of Science Education, 19, 697-710.

Roletto, E. and Piacenza, B. (1994) Faut-il construire le concept de substance? Aster, 18, $63-74$.

Sannmarti, N., Izquierdo, M. and Watson, R. (1995) The substantialisation of properties in pupils' thinking and in the history of science. Science Education, 4, 349-369.

Solomonidou, C. (1991) Comment se representer les substances et leurs interactions? $\mathrm{PhD}$ thesis, Université Paris VII.

Solsona, N. (1997) The emergence of the interpretation of chemical phenomena (Barcelona: Autonoma University of Barcelona).

Solsona, N. and Izquirdo, M. (1993) What is conserved in a chemical change? Opinions of Secondary School Students. In B. Gowin (ed.) Third International Seminar of Misconceptions and Educational Strategies in Science and Mathematics (New York: Cornell University).

Solsona, N. and Izquirdo, M. (1998) La conservación del elemento, una idea inexistente en el alumnado de secundaria. Alambique, 17, 76-84.

Stavridou, H., Solomonidou, C. and Papademetriou, V. (1993) Student-teachers conceptions about physical and chemical matter transformation. In Book of Abstracts of the European Conference on Research in Chemical Education, 49, 27-37.

Thagard, P. (1990) The conceptual structure of the chemical revolution. Philosophy of Science, 57, 183-209.

VAn Dıјк, T. A. (1978) Tekstwetenschap. Een interdisciplinaire inleiding (Amsterdam: Het Spectrum).

Watson, R. et al. (1995) The Effect of Practical Work on Students' Understanding of Combustion. Fournal of Research in Science Teaching, 32, 487-502.

White, R. (1996) The link between the laboratory and learning. International fournal of Science Education, 17, 761-774. 
Copyright $\odot 2003$ EBSCO Publishing 